\section{VISUALISED NUMERALS}

T HAVE lately been occupied in eliciting the degree and manner in which different persons possess the power of seeing images in their mind's eye, and am collecting a large and growing store of materials, partly of verbal answers made by friends to my inquiries, but principally by means of written replies to a printed list of questions that I am distributing. The subject bears in many ways upon psychological and ethnological studies, and I should be glad if the present memoir upon one particular branch of it should induce correspondents to furnish me with authentic information of the kind I seek.

The various ways in which numerals are visualised is but a small subject, nevertheless it is one that is curious and complete in itself. My data in respect to it are already sufficiently numerous to be worth recording, and they will serve to show that parallel results admit of being arrived at in other directions.

I may begin by mentioning one or two general experiences. I have been astonished. to find how superior women usually are to men in the vividness of their mental imagery and in their powers of introspection. Though I have admirable'returns from many men, I have frequently found others, even of the highest general ability, quite unable for some time to take in the meaning of such simple questions as these. "Think of some definite object,- say your breakfast table, as you sat down to it this morning, and consider carefully the picture that rises before your mind's eye. Is the image dim, or fairly clear? Is its brightness comparable to that of the actual scene? Are the objects sharply defined? Are the colours quite distinct and natural, \&c.?" On the other hand, I find the attention of women, especially women of ability, to be instantly aroused by these inquiries. They eagerly and carefully address themselves to consider their modes of thought, they put pertinent questions, they suggest tests, they express themselves in well-weighed language and with happy turns of expression, and they are evidently masters of the art of introspection. I do not find any peculiar tendency to exaggeration in this matter either among women or men; the only difference I have observed between them is that the former usually show an unexpected amount of intelligence, while many of the latter are as unexpectedly obtuse. The mental difference between the two sexes seems wider in the vividness of their mental imagery and the power of introspecting it, than in respect to any other combination of mental faculties of which I can think.

Another general experience is that the power of seeing vivid images in the mind's eye has little connection with high or low ability or any other obvious characteristic, so that at present I am often puzzled to guess from my general knowledge of a friend, whether he will prove on inquiry to have the faculty or not. I have instances in which the highest ability is accompanied by a large measure of this gift, and others in which the faculty appears to be almost wholly absent. It is not possessed by all artists; nor by all mathematicians, nor by all mechanics, nor by all men of science. It is certainly not possessed by all metaphysicians, who are too apt to put forward generalisations based solely on the experiences of their own special ways of thinking, in total disregard of the fact that the mental operations of other men may be conducted in very different ways to their own.

I have much to say on this and cognate topics which I pass by on the present occasion, that I may at once proceed to the subject of this paper. The first section of it is of minor interest and may be quickly dismissed. It is the power of mentally seeing numerals, of holding them fast in the field of view, of perusing them when there, and of working sums by mental imagery in the same form as that in which they are usually carried on with pen and paper.

Here is a well marked case of the power of visualising numerals. The writer is an office-bearer of one of our scientific societies:-

I. If words such as fifty-six be spoken, I most clearly, easily and instantly visualise the figures. I do so almost automatically. I perceive that when I speak the word "thousand" or hear it spolken, the figures at once group themselves together. I find it quite impossible to think of the date of a year without remembering and visualising the figures, though I express myself in words. The figures are always printed; in type and size they resemble those commonly used for the headings of newspapers. I cannot, however, appreciate a back-ground, the figures appear simply in space. I think that by practice and concentration I could hold fast many figures.

The next is by a friend who has a most tenacious memory for numerical administrative details :-

2. I can see and mentally retain many figures, and can multiply four figures by four figures without practice, the operation proceeding visibly in my mind like a sum upon paper.

The following is by a school boy who is a near relation of a man of the highest mark in science :-

3. I can visualise a fairly long line of figures, and I do mental sums by putting down the working of them in my mind's eye, up to square roots with two figures in the root, and in algebra, to simple quadratics.

A schoolmistress writes:-

4. I can retain several figures in my mental view and work examples, seeing every figure in the process.

A late Fellow of Trinity College, Cambridge, states :-

5. All arithmetical processes performed mentally, are exactly the processes I should perform on paper.

It must not, however, be imagined for a moment, that the processes of mental arithmetic are necessarily wholly dependent on the faculty of visualising numerals. Here is a good instance to the contrary. 'The writer is the author of a valuable work on a branch of Mental Philosophy :-

6. The numerals are merely ideal sounds [to me], not ideal sights in any way, I have, or used to have, very considerable powers of mental arithmetic arid mental algebra, but always used in thought the sounds of the signs. In the process I always forgot every step as soon as 1 had reached the result of that step.

This last sentence is exceedingly suggestive, and reminds one that many so-called "unconscious" acts are not really unconscious, but are acts characterised by an exceedingly brief and evanescent period of consciousness.

The processes of mental arithmetic are commonly dependent on the representation of more than one sense, as in the following instance :-

7. I can multiply with effort four figures by four; but partly only by 1 mages, chiefly by memory.

I am as yet unable to determine the percentage of persons who possess in the various degrees, the power of visualising numerals, because my returns are chiefly derived from persons who are exceptionally gifted An excellent way of obtaining average returns to psychological questions would be by the help of schoolmasters, who have an admirable field of psychological research immediately before them, which they wholly neglect. If a hundred boys in a large school could be set simultaneously to answer such questions as those I am putting, after their masters had cl arly explained their purport to them, and had taken common precautions to insure independent replies, and to sift away lax and untrustworthy statements, the thing would be effected by a single stroke, and both boys and masters would enjoy the satisfactory feeling of having accomplished a substantial piece of scientific research.

I have many curious cases of colour association with the various numerals, but shall only give a very few instances of them, and those incidentally, in the present paper. I shall also abstain at present from speaking of the many different ways in which dates, days of the week, and months of the year are apt to be visualised. 
The topic to which I especially wish to direct attention, is the innate and hereditary tendency of certain persons to see numbers in definite and constant arrangements or schemes, whose various characters will be easily understood from the extracts I am about to give and by the accompanying illustrations, which are reductions to a small scale of the pictures I have received, with a necessary sacrifice of detail in a few cases.

The simplest instances do not seem to be the commonest; thus, I have very few indeed that could be classed with the following :-

8. When a child, I counted by means of imaginary cards from ace to ten. My little boy in the same way, used an imaginary domino.

\section{Or this :-}

9. I picture numbers in groups, thus 5 is sometimes $: \because$, sometimes $\because ., 8$ is $:: \vdots, 7$ is $\vdots \vdots$, , 100 is ten rows of ten.

I may as well give the remainder of this communication here; it is written by a lecturer upon mental philosophy. He says :-

Io. The numerals $1,2,3,4, \&$ c., from the part they play in the multiplication table, have been personified by me from child hood. 9 is a wonderful being of whom I felt almost afraid, $8 \mathrm{I}$ took for his wife, and there used always to seem a fitness in $9 \times 9$ being so much more than $8 \times 8$. 7 again is masculine; 6 , of no particular sex but gentle and straightforward; 3 , a feeble edition of 9 , and generally mean ; 2 , young and sprightly ; 1 , a common-place drudge. In this style the whole multiplication table consisted of the actions of living persons, whom I liked or disliked, and who had, though only vaguely, human forms.

The schemes in which numerals appear are usually fantastical and sometimes very elaborate. I will (by permission) give the name of the writer of the first instance about to be adduced, on account of the hereditary interest that is attached to it. It is by Mr. George Bidder, Q.C., a son of the late eminent engineer, who was known in early life as the calculating boy. Mr. George Bidder inherits much of his father's marvellous power of mental arithmetic, being able, though not with equal precision and rapidity, to mentally multiply fifteen figures by another fifteen figures. This faculty has been again transmitted, though in an again reduced degree, to the third generation. (See letter in the Spectator, December 28, 878 , also the early numbers of that paper in 1879.$)$

He writes to me as follows :-

11. One of the most curious peculiarities in my own case, is the arrangement of the arithmetical numerals. I have sketched this to the best of my ability. Every number (at least within

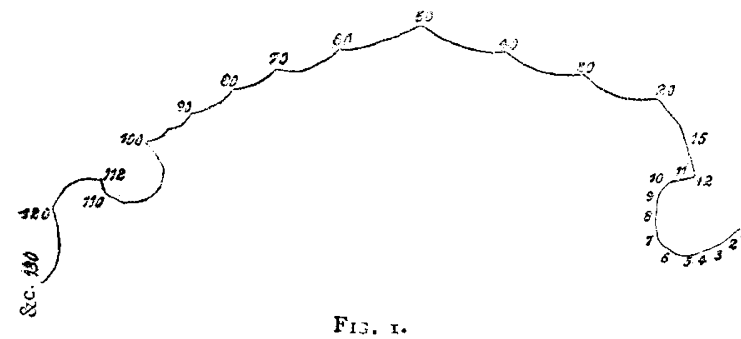

the first thousand, and afterwards thousands take the place of units) is always thought of by me in its own definite place in the series, where it has if I may say so, a home and an individuality. I should, however, qualify this by saying that when I am multiplying together two large numbers, my mind is engrossed in the operation and the idea of locality in the series for the moment sinks out of prominence. You will observe that the first part of the diagram roughly follows the arrangement of figures on a clock-face, and I am inclined to think that may have been in part the unconscious source of it, but I have always been utterly at a loss to account for the abrupt change at 10 and again at 12 .

It occurs to me that the change is probably due to the wrench given to the mental picture of the clock dial in order to make its duodecimal arrangement conform to the decimal system, and that the same action is repeated at IIO.

The next diagram exhibits the most compact of all the mental schedules which I have as yet received :-

12. The representation I carry in my mind of the numerical series is quite distinct to me, so much so that I cannot think of any number but $I$ at once see it (as it were) in its peculiar place in the diagram. My remembrance of dates is also nearly entirely dependent on a clear mental vision of their loci in the diagram. This, as nearly as I can draw it, is the following :-

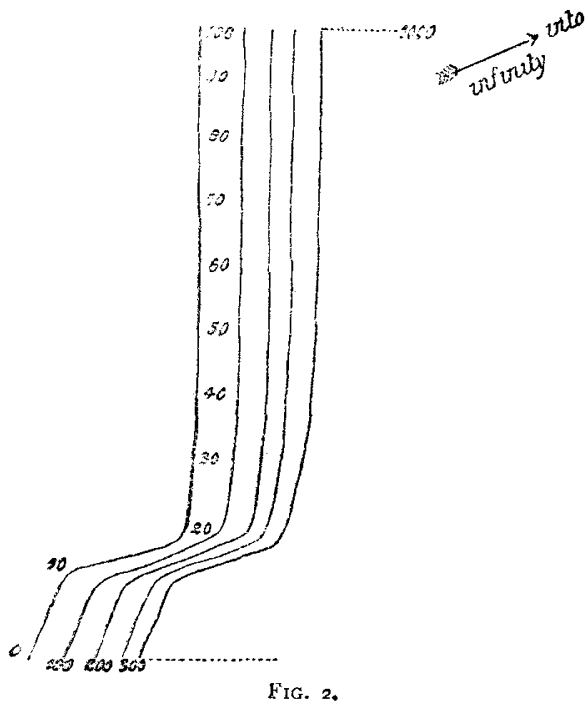

It is only approximately correct (if the term " correct" be at all applicable). The numbers seem to approach more closely as I ascend from 10 to $20,30,40, \& \mathrm{c}$. The lines embracing a hundred numbers also seem to approach as I go on to 400,500 , to $I, 000$. Beyond I, 000 I have only the sense of an infinite line in the direction of the arrow, losing itself in darkness towards the millions. Any special number of thousands returns in my mind to its position in the parallel lines from I to 1,000 , The diagram was present in my mind from early childhood; I remember that I learnt the multiplication table by reference to it, at the age of seven or eight. I need hardly s?y that the impres. sion is not that of perfectly straight lines, I have therefore used no ruler in drawing it.

Some writers have somewhat rashly asserted that our idea of numbers is always based on our ten fingers and ten toes. There are, however, other forms in use by various nations than those of decimal arithmetic, and the last paragraph of the foregoing seems sufficient to show that the finger and toe hypothesis is not universally true. This opinion was strongly maintained by the lady writer of the following remarks, whose imagery dates beyond her earliest recollections:-

13. The annexed column [a portion only of it is represented here] represents how I see the numbers from I to 140. There is no break up to 30 , and none from 90 to 130 , but $I$ think this is because the three figures at 100 make a sort of break of themselves. After I 40 they go on regularly, but farther off. The figures are not one above the other, as they appear in the diagram, but are one beyond the other, stretching away into space. They are about half an inch long, of a light grey colour on a darker and brownish grey ground.

The next example is very curious; the diagram which accompanies it is carefully and minutely drawn on a large sheet of paper and looks like a detailed route survey made by a careful traveller. I have been obliged to treat it much as a map maker Frg. 3. would treat such a survey. 
14. I find it very difficult to represent my visualisation of numerals diagrammatically. I scarcely ever see the lower numbers written ; I simply know exactly where $6,7,4, \& c$, , are to be found. I cannot properly represent the crowding of numbers in some places, nor the edgewise positions they occupy, nor can I at all adequately express the compactness and yet extent of the line. On either side of it there seems to be indefinite space. But there is a boundary at I, beyond which I have to look for minus quantities. After 108 the notion of place becomes hazy and indistinct, though $I$ can visualise the higher numbers in respect to their position, if I make the effort. I think of a million as very far off and high up. When multiplying for example $5 \times 6$, I know instantly the spot where the product will
15. From the very first I have seen numerals up to nearly 200 , range themselves always in a particular manner, and in thinking of a number it always takes its place in the figure. The more attention I give to the properties of numbers and their interpretations, the less I am troubled with this climsy framework for them, but it is indelible in my mind's eye even when for a long time less consciously so. The higher numbers are to me quite abstract and unconnected with a shape. This rough and untidy production is the best I can do towards representing what I see. There was a little difficulty in the performance, because it is only by catching oneself at unawares, so to speak, that one is quite sure that what one sees is not affected by temporary imagination. But it does not seem much like, chiefiy because the mental picture
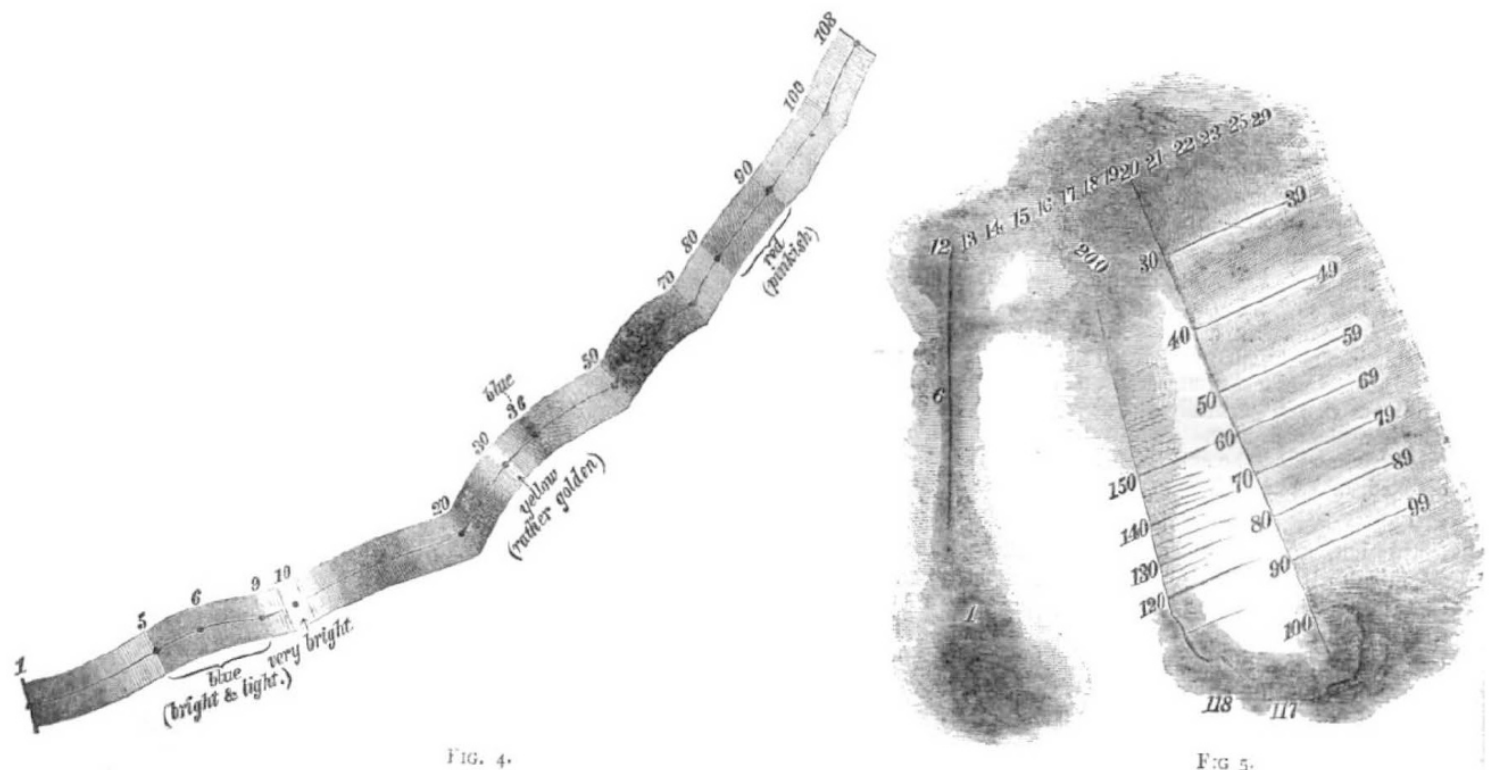

be, and look to see what number it is. But if asked to multiply $14 \times 17$ I first go up to the place whereabouts I expect it will be, and am baffled. I do not know where to look. In the coloured parts, it is the place rather than the number that is coloured, and the number is connected with colour because it happens to be in that place. The brightness and darkness may possibly in the lower numbers have some connection with the events of my life, the numbers which correspond to years of my age which were eventful, being as a rule much more distinct. As a child $I$ had great liking for the number six, arising I fancy from a keen desire to be six years old. I had also an excessive love for blue, so perhaps this accounts for the connection between them. N.B.-I learnt arithmetic in a thorough old-fashioned unintelligent style, the first step being to learn to count without the least conception as to what the numbers meant.

The writer of the foregoing has two sisters and a brother. One of the sisters sees numerals in a differently arranged diagram, and the figures themselves are coloured, (1) black, (2) white, (3) yellow, (4) red, (5) greenish yellow, (6) blue, (7) black, (8) red, (9) grey, (o) gold. The other sister has a fainter, but still a decided tendency to see figures in a mental diagram. It is without colour but has variations of shade. The brother has a definite diagram of numbers arranged in a line sloping upwards to the right as far as 120 , and absolutely devoid both of colour and variations of shade. No trace of these colour-peculiarities has yet been made out on either the father or the mother's side, but there is a tendency in both father and mother to visualise in diagrams.

The effects of heredity are also strongly marked in the next set of instances, consisting of two families of cousins. A sister in the first family writes :- - never seems on the flat but in a thick, dark grey atmosphere deepening in certain parts, especially where I emerges, and about 20. How I get from Ioo to I 20 I hardly know, though if I could require these figures a few times without thinking of them on purpose, I should soon notice. About 200 I lose all framework. I do not see the actual figures very distinctly, but what there is of them is distinguished from the dark by a thin whitish tracing. It is the place they take and the shape they make collectively which is invariable. Nothing more definitely takes its place than a person's age. The person is usually there so long as his age is in mind.

\section{Another sister says :-}

16. I always see figures ascending in a directly perpendicular line in front of my eye [according to the sketch and memorandum sent in illustration, which it is hardly necessary to reproduce, the I stands opposite to the eye, and the scale reaches vertically up to 1,000$]$. Then all becomes vague, but $I$ know that the thousands and tens of thousands are not in the same perpendicular line, and I believe they turn to the left hand.

A maternal aunt of these ladies "sees figures in a diagrain," which has not yet reached me, and the other family that I am now about to mention are the children of a maternal uncle. There are three sisters and a brother who have the same faculty in varying degrees.

The brother writes from Cambridge :--

17. Numerals are always pictured by re in a straight line from left to right. They are black, on a ground varying in illumination, which is briebt up to 10 , then getting very shady from 10 to $20 ; 20$ to 40 , bright ; 40 to 60 , moderate; 60 to 80 , shady. Shadiest are from ro to 20,60 to 80 or 90, I, 000 to 
2,000 . The millions are in a vague, bright distance to the right.

One of the sisters writes:-

18. Figures present themselves to me in lines as in the annexed diagram]. They are about a quarter of an inch in length,

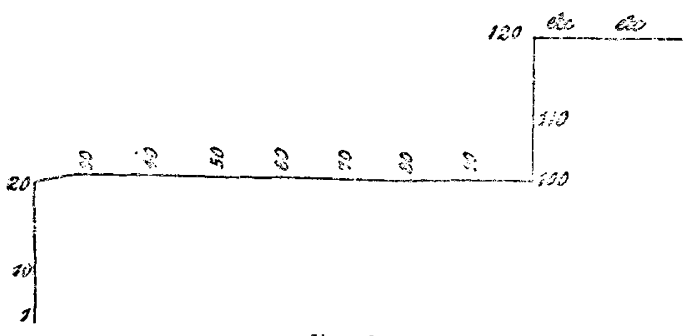

Fig 6

and of ordinary type. They are black on a white ground. 200 generally takes the place of IOO and obliterates it. There is no light or shade, and the picture is invariable.

Another sister gives a picture in which the numbers form a vertical line from I, opposite to the eye, up to 100 , at which point the scale appears to recede from her.

The third sister writes :-

I9. Figures always stand out distinctly in Arabic numerals ; they are black on a white ground, of this size [the specimen was

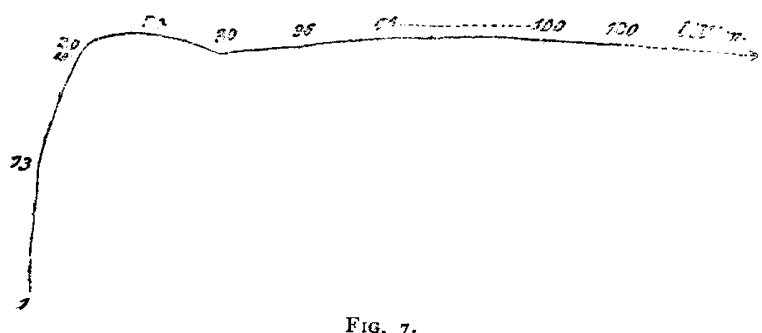

FIG. 7.

clear and round, and in rather large ordinary handwriting], but the numeral 19 is smaller than the rest.

It is curious that the lines of most of the diagrams I have thus far given should be so feeble and, to appearance, wandering, although as a matter of fact they are firmly fixed. Artists speak of the "leading lines" in a picture, and commend pictures in which the leading lines are graceftul. I have little doubt that one of the reasons why minds vary in artistic power is that the leading channels in the blank schedules of their minds vary in character. I should expect that natural artists might be found whose habit was to visualise numerals not in shaky lines, but in bold and beautiful curves. In the instances I am about to give, especially in the first of them, there is more tendency to geometric precision, and I should be most curious to learn (by actual and careful test) whether or no such cases are generally correlated with a true eye to straightness, squareness, and symmetry.

In the following example the numbers are not associated with visual figures, but with points on an ascending and descending scale, which is a pure line having neither breadth nor colour. It is described as perfectly flexible and extensible, much, I suppose, as if it were printed on a strip of india-rubber sheeting, and it is applicable to the measurement of large distances or small ones, to fractions, and to straight lines or curves. A very curious description is given in detail, which 1 will not here reproduce, of the way in which the scale is used in mental arithmetic. The writer adds :-

20. The accompanying figure lies in a vertical plane, and is the picture seen in counting. The zero point never moves, it is in my mind; it is that point of space known as "here," while all other points are outside or "there." When I was a child the zero point began the curve; now it is a fixed point in an infinite circle... I have had the curious bending from o to

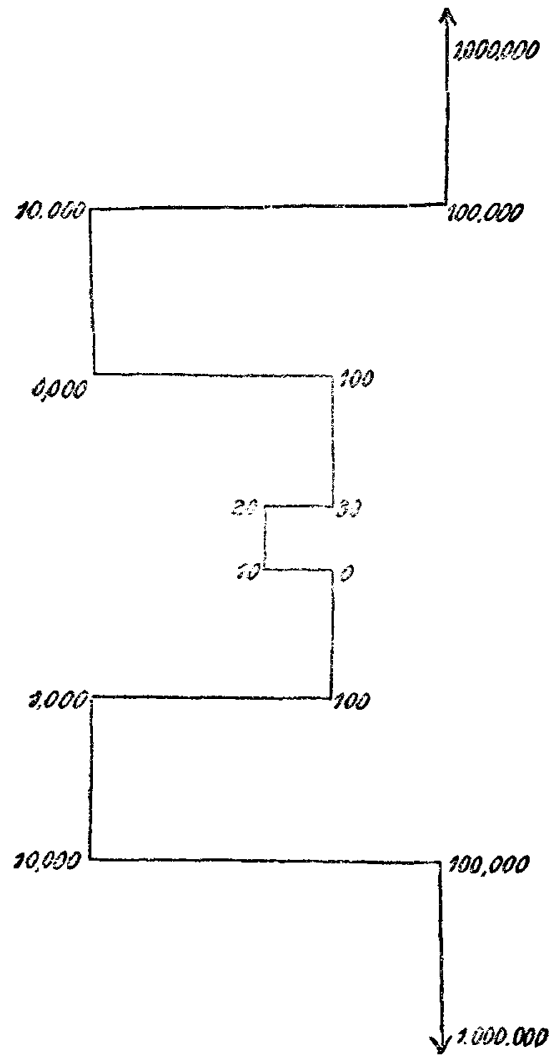

Frg. 8.

30 as long as I can remember, and imagine each bend must mark a stage in early calculation. It is absent from the negative side of the scale, which has been added since childhood.

Another correspondent sees figures in a circle, having o at the right hand of its horizontal diameter and 100 at the left hand. Positive numbers are reckoned from o to 100 from the right, over the top to the left, and negative numbers the other way. The same takes place with figures between 100 and 200,200 and $300, \& \mathrm{c}$.

Another correspondent sees them for the most part in a regular row like park palings. The description and sketch are as follows:-

2I. As far as 12 the numerals appear to be concealed in black shadow; from 12 to 20 is illuminated space, in which I can distinguish no divisions. This I cannot illustrate, because it is simply cark and light space, but with a tolerably sharp line of division at $\mathbf{2} 2$. From 20 to 100 the numerals present themselves as follow:, but less distinctly :-

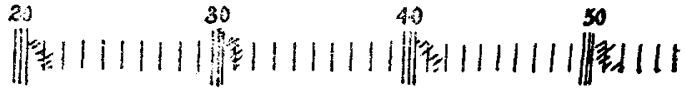

$$
\begin{aligned}
& \text { Fig. 9. }
\end{aligned}
$$

An account is appended of the way in which simple mental arithmetic is effected by this arrangement, which at present I pass over.

I will conclude my list with a statement written by a mathematical astronomer of rapidly rising reputation, whose "practice of working arithmetic" mentioned in the concluding paragraph must be understood to signify "performing masses of laborious calculations":-

22. The numbers $1,2,3,4, \& c$., are in a straight row, and I 
am standing a little on one side. They go away in the distance' so that 100 is the farthest number I can see distinctly. It is dusky grey, and paler near to me ; up to 20 it occupies a disproportionate size. There are sorts of woolly lumps at the tens. These pictures are not of such frequent occurrence in my mind as formerly. The practice of working arithmetic has rather expelled them.

Since the foregoing remarks were first sent to the printer, many additional cases have reached me, which I regret to have no space left to include. One very interesting group consists of three cousins and the daughter of one of them. Another case was brought to my notice by a correspondent; it was published in the Atlantic Monthly, February, 1873, p. 199, with an accompanying diagram, and is signed by Miss $H$. R. Hudson. I have little doubt that many allusions to the faculty of visualising numerals in diagrammatic and coloured shapes might be found to exist scattered here and there in various books.

Of the many results to be drawn from the foregoing extracts, I do not at present care to dwell upon more than these. In the first place I am sure that all will agree with me in saying that the descriptions bear evident marks of careful and trustworthy observation. In the second place, although they refer to characteristics which the majority of my readers may not possess, their language is sufficiently clear to convey a good idea of what is meant to be conveyed. In the third place, these independent statements powerfully corroborate and explain one another. Therefore, although philosophers may have written to show the impossibility of our discovering what goes on in the minds of others, I maintain an opposite opinion. I do not see why the report of a person upon his own mind should not be as intelligible and trustworthy as that of a traveller upon a new country, whose landscapes and inhabitants are of a different type to any which we ourselves have seen. It appears to me that inquiries into the mental constitution of other people is a most fertile field for exploration, especially as there is so much in the facts adduced here, as well as elsewhere, to show that original differences in mental constitution are permanent, being little modified by the accidents of education, and that they are strongly hereditary.

I trust, therefore, that the publication of this memoir may prove to be the means of inducing some persons to furnish me with information of the kind 1 am now seeking. I want to hear of well-marked and properly-authenticated instances of persons who are able to recall, or represent to their imagination, with great vividness, either sights, sounds, smells, or tastes, and to obtain information that may throw light on the peculiarities of the representative faculty in different families and races.

\section{2, Rutland Gate, London}

\section{FRANCIS GALTON}

\section{ON A MODE OF EXPLAINING THE TRANS VERSE VIBRATIONS OF LIGHT}

THERE has been considerable difficulty in arriving at a satisfactory conception of the means by which the transverse vibrations of light are produced in the ether. In the attempt to surmount this difficulty some have gone so far as to conjecture that this structure of the ether nust resemble that of a solid; for it was imagined that nothing but such a structure could propagate transverse vibrations. Yet the supposition of the ether being anything like a solid appears to be in direct antagonism to the evidence of our senses; for we move about so freely in this "solid" as to be unconscious even of its existence.

My object here is to direct attention more especially to a suggestion thrown out by the late Prof. Clerk Maxwell in regard to this point. This suggestion is contained in the article, "Ether," in the new edition of the "Encyclopædia Britannica," in connection with a notice of a theory of the constitution of the ether (considered in special relation to the problem of gravitation) by the present writer, and published in the Philosophical Magazine for September and November, 1877, and February, 1878. After referring to the fact that the present writer "has supposed that the ether is like a gas whose molecules very rarely interfere with each other, so that their mean path is far greater than any planetary distances," Prof. Maxwell continues as follows:-

"He has not investigated the properties of such a medium with any degree of completeness, but it is easy to see that we might form a theory in which the molecules ${ }^{1}$ [atoms of ether] never interfere with each other's motion of translation, but travel in all directions with the velocity of light; and if we further suppose that vibrating bodies have the fower of impressing on these atoms of ether some vector property (such as rotation about an axis) which does not interfere with their motion of translation, and which is then carried along by the atoms of ether, and if the alternation of the average value of this vector for all the atoms of ether within an element of volume be the process which we call light, then the equations which express this average will be of the same form as that which expresses the displacement in the ordinary theory."

There is one point in the above suggestion I would briefly remark upon, viz., the supposition made by Prof. Maxwell that the atoms of ether "never interfere with each other's motion of translation "[i.e., never encounter each other]. This supposition seems to have been called for by the fact previously mentioned in the same article "Encyc. Brit.," p. 572), viz., that "the ether transmits transverse vibrations to very great distances without sensible loss of energy by dissipation," whereas it is contended that if the ether atoms encountered each other (frequently at least), "the energy of the regular vibrations would be frittered away into that of the irregular agitation which we call heat." But I would venture to suggest that, as we have no proof that no dissipation whatever of the energy of light takes place in long distances (but perhaps even some indication to the contrary), it would appear evident that no necessity really exist 3 for supposing that the atoms of ether never interfere with each other's motion of translation. I think it will be admitted as a reasonable conclusion that so long as the dissipation of the energy (of the light) attendant on the mutual encounters of the ether atoms is no greater than observation allows us to suppose it to be, all conditions are satisfied. Moreover, it would seem that to suppose the ether atoms never to interfere with each other's motion of translation would be equivalent to assuming that their mean path is indefinitely great, which appears to involve the assumption that the atoms have no finite size or dimensions, which would put a difficulty in the way of a satisfactory or consistent corception of matter. On this ground I would therefore suggest that the atoms of ether may be considered to have a reasonably long free path [which may be conceived as great as we please, by simply conceiving the atoms small], and thus the dissipation of the energy of the light may be reduced within the limits required by observation. This does not alter in the least in its essential details the above suggestion by Prof. Maxwell as to the mode of production of the transverse vibrations of light, which I would accordingly enlarge upon and elaborate somewhat here (in connection with the special structure of gross matter required by the physical theory of gravity). First it is important to observe that many observed facts lead us to infer that gross matter (probably the molecules ${ }^{2}$ themselves) possesses a more or less open structure (or possesses a high degree of porosity). The transparency of some bodies, the free passage of the magnetic disturbance through all bodies,

I I merely substitute "atoms of ether" in the above passage for "molecules," to avoid any possible ambiguity, as the word "molecules" is often applied to the parts of gross matter.

2 This is also in harmony with the modern theory of vortex-atoms. 